\title{
ECONOMIAS DE ESCALA E ESCOPO NA PREVIDÊNCIA COMPLEMENTAR FECHADA BRASILEIRA
}

\author{
Marcelo Abi-Ramia * \\ ROGÉrIo BOUERI ${ }^{\dagger}$ \\ Adolfo SACHSIDA $\ddagger$
}

\begin{abstract}
Resumo
Este trabalho identifica a existência de economias de escala e escopo na previdência complementar fechada brasileira por meio da realização de um conjunto de testes quantitativos realizados sobre a base de dados administrativos disponibilizada pelo Ministério da Previdência Social. Serão apresentados a revisão da literatura internacional, as estatísticas descritivas da base de dados, o modelo teórico para existência de economias de escala em previdência complementar fechada, os métodos quantitativos aplicados, seus respectivos resultados e uma seção com implicações normativas. Os resultados econométricos apontam para a existência de economias de escala na previdência complementar fechada brasileira mais expressiva que na literatura internacional.
\end{abstract}

Palavras-chave: Economias de Escala; Previdência Complementar; Eficiência.

\begin{abstract}
This work identifies the existence of economies of scale and scope for the Brazilian complementary pension funds via quantitative tests on the administrative data base of the Ministry of Social Security. A literature review, a descriptive statistics of the data base, a theoretical model on the existence of economies of scale in complementary pensions, the quantitative methods used, its results and the normative implications will be presented. Econometric results show that economies of scale on Brazilian complementary pensions are stronger than in the rest of the world.
\end{abstract}

Keywords: Economies of Scale; Complementary Pensions; Efficiency. JEL classification: G23, J26, H55

DOI: http://dx.doi.org/10.1590/1413-8050/ea 132623

\footnotetext{
* Instituto de Pesquisa Econômica Aplicada — IPEA. E-mail: marcelo.caetano@ipea.gov.br

† Instituto de Pesquisa Econômica Aplicada — IPEA. E-mail: rogerio.boueri@ipea.gov.br

‡ Instituto de Pesquisa Econômica Aplicada — IPEA. E-mail: adolfo.sachsida@ipea.gov.br
} 


\section{Introdução}

O objetivo deste artigo é identificar a existência de economias de escala e escopo na previdência complementar fechada brasileira por meio da realização de um conjunto de testes quantitativos. A implicação prática deste estudo consiste no auxílio à definição da política da previdência complementar de modo que se gerem os incentivos apropriados ao repasse dos ganhos de escala aos participantes e pensionistas ${ }^{1}$, o qual lhes permitirá redução do custeio administrativo com a consequente elevação do valor dos benefícios de aposentadoria e pensão. O tamanho do setor, cujos ativos perfazem $14 \%$ do PIB brasileiro, constitui-se em motivação adicional para a realização de estudo acerca de suas características específicas.

Economias de escala ocorrem em situações em que há redução dos custos médios à medida que a produção aumenta. Conceito também relevante e explorado no artigo se refere a economias de escopo. Essas se verificam caso o custo de uma mesma firma ofertar dois produtos distintos seja inferior ao custo desses dois produtos serem produzidos por firmas distintas. No caso concreto deste trabalho, pode ser mais econômico que uma mesma entidade previdenciária oferte dois planos distintos de benefícios a criar uma nova entidade para gerir o novo plano.

O benefício auferido pelo participante decorre do fato dessas economias permitirem a redução do custeio administrativo, o que implica menores taxas de administração e valores mais elevados de suas aposentadorias e pensões. Cálculos realizados pelos autores deste texto indicam que cada ponto percentual de elevação da taxa de administração reduz a reserva acumulada durante 30 anos em aproximadamente $16 \%$.

O ineditismo do trabalho consiste na identificação da existência de economias de escala e escopo na previdência complementar fechada no Brasil. Ao contrário do caso brasileiro, a literatura internacional apresenta artigos que já analisaram a existência de economias de escala na previdência complementar em países como EUA, Holanda, Austrália, Canadá, Singapura e Suécia. Mesmo para o caso internacional, a quantidade de artigos escritos sobre o tema não é abundante. A principal razão para isso é a dificuldade de obtenção de dados.

O primeiro trabalho empírico realizado sobre o tema foi Caswell (1976) que analisou o impacto da escala nos planos de previdenciários estadunidenses para os anos de 1969 e 1970 . Os resultados indicaram valor de 0,8 para a elasticidade do custo administrativo em relação ao número de participantes. Esse coeficiente indica a existência de economia de escala dado que o custo total cresce menos que proporcionalmente à variável independente assumida como produto.

\footnotetext{
${ }^{1}$ Para fins de elucidação, apresenta-se terminologia referente à previdência complementar fechada brasileira. A filiação à previdência complementar fechada é facultativa e restrita a dois grupos: (i) empregados de empresa ou ente da federação que criou entidade fechada de previdência complementar (EFPC) ou (ii) filiados a sindicato ou entidade de classe que instituiu EFPC. Participante se refere tanto ao trabalhador ativo quanto ao aposentado filiado a uma EFPC. Pensionista é aquele em gozo de pensão por morte. Beneficiário é o grupo formado por aposentados e pensionistas. Patrocinador é a empresa ou ente da federação que institui EFPC. Caso a empresa seja privada, o patrocinador é privado; caso contrário, público. Instituidor é sindicato ou entidade de classe que criou EFPC. Caso haja somente um patrocinador, a entidade é de patrocínio singular; caso contrário, multipatrocinada. Não há limites à quantidade de plano de benefícios que podem ser ofertados por uma mesma EFPC.
} 
Mitchell \& Andrews (1981) foi outro estudo pioneiro efetuado na sequência e também aplicado às entidades fechadas de previdência complementar (EFPC) dos EUA com regressão seccional para o ano de 1975. Os resultados apontaram para ganhos de escala mesmo com os autores tendo assumido dois produtos para um fundo de pensão: quantidade de participantes e ativos administrados. A elasticidade do custo administrativo em relação ao número de participantes foi de 0,56 e em relação aos investimentos ficou em 0,27.

Hsin \& Mitchell (1997) adotaram o método de fronteira estocástica para a função custo para EFPC dos EUA. Os resultados apontaram para a existência de ganhos de escala tanto em relação à quantidade de participantes - com elasticidade de 0,74- quanto para os ativos financeiros — cuja elasticidade atingiu 0,49 .

Bateman \& Mitchell (2004) apresentam evidências para o caso australiano. Encontraram valores de 0,4 e 0,5 para a elasticidade do custo administrativo em relação ao número de participantes e ao total de ativos financeiros, indicando presença de economias de escala na Austrália.

O impacto da escala para o caso holandês foi analisado por Bikker \& Dreu (2009) com base em econometria para um painel não balanceado de 1992 a 2004. A elasticidade de escala equivaleu a 0,64 em relação ao número de participantes.

Bikker et al. (2012) é outro estudo sobre o tema no qual também se indica a existência de economias de escala. O coeficiente do total de participantes foi 0,67 e do total de ativos foi 0,19 .

Há estudos para outros países que também apontam para a existência de economias de escala, mas o fazem por meio de estatísticas descritivas e fundamentação conceitual. São os casos de Björkmo \& Lundbergh (2010) para a Suécia e Koh et al. (2008) para Singapura.

A presença de economias de escala nas EFPC é consenso na literatura internacional independentemente da região geográfica, do período de realização do estudo e da técnica estatística utilizada. O presente artigo realiza testes empíricos que indicam que esse fenômeno também se passa no Brasil tanto nas economias de escala quanto nas de escopo.

Como forma de melhor estruturar os fundamentos teóricos e empíricos, o artigo subdivide-se em seções, além desta introdução. A segunda seção apresentará estatísticas descritivas da base de dados usada no artigo. A terceira descreve o modelo teórico para existência de economias de escala em previdência complementar. A quarta apresenta os métodos quantitativos aplicados e seus respectivos resultados. Por fim, as duas últimas seções apresentam as implicações normativas e considerações finais deste trabalho.

\section{Estatísticas da previdência complementar fechada no Brasil}

2

As estatísticas aqui descritas se baseiam em dados gentilmente cedidos pela Secretaria de Políticas de Previdência Complementar (SPPC) do Ministério da Previdência Social (MPS) ${ }^{3}$. Essa base também serviu para a realização

\footnotetext{
${ }^{2}$ Para conhecimento introdutório das normas institucionais que regulamentam as EFPC, recomenda-se a leitura de da Previdência Social (2008) e da Previdência Social (2011). Para leitura mais aprofundada, há de se ver a legislação em Brasil (1977), Brasil (1978), Brasil (1997), Brasil (2001a), Brasil (2001b), Brasil (2004), Brasil (2009a), Brasil (2009b), Brasil (2012).

${ }^{3}$ Apresenta-se sumário das estatísticas descritivas em apêndice ao final do texto.
} 
dos testes econométricos apresentados na seção 4, os quais complementam as estatísticas básicas apresentadas na presente seção. Há informações de natureza cadastral e contábil referentes ao biênio 2010-2011. Em 2010, o cadastro apresentou 277 - EFPC, número reduzido para $271 \mathrm{em} \mathrm{2011.} \mathrm{O} \mathrm{total} \mathrm{de} \mathrm{en-}$ tidades no biênio foi 283 , mas somente 265 operaram simultaneamente em 2010 e 2011.

A distribuição da quantidade de participantes e pensionistas por EFPC é um indicativo da existência de ganhos de escala no setor. De fato, somente $8 \%$ das entidades têm número total de participantes e pensionistas inferior a um milhar e apenas uma conta com menos de 100 participantes e pensionistas. Tal fato pode ser indício de escala mínima para viabilidade do setor. Outro dado relevante é a diminuta participação da complementação previdenciária na sociedade brasileira. Números do MPS indicam que o Regime Geral de Previdência Social (RGPS) atendia em 2011 a creca de 67 milhões de pessoas entre contribuintes e beneficiários ${ }^{4}$. Comparativamente, a quantidade de participantes e pensionistas das EFPCs sequer chegou a 500 mil pessoas, ou seja, nem $1 \%$ do público do RGPS. A junção desses dois fatos (pequena presença de EFPC com poucos participantes e baixa participação da previdência complementar fechada no público brasileiro) indica que o estímulo a entidades multipatrocinadas pode trazer ampliação da cobertura da previdência complementar no Brasil.

Tabela 1: Distribuição das EFPC por Quantidade de Participantes e Pensionistas: 2010-2011

\begin{tabular}{lrr}
\hline Quantidade de Participantes e Pensionistas & \multicolumn{1}{r}{2010} & \multicolumn{1}{c}{2011} \\
\hline $0-100$ & 1 & 1 \\
$100-500$ & 11 & 12 \\
$500-1000$ & 10 & 9 \\
$1000-2500$ & 38 & 33 \\
$2500-5000$ & 45 & 45 \\
$5000-10000$ & 57 & 54 \\
$10000-20000$ & 42 & 40 \\
$20000-30000$ & 30 & 29 \\
$30000-40000$ & 7 & 9 \\
$40000-50000$ & 9 & 9 \\
$>50000$ & 27 & 30 \\
Total & 277 & 271 \\
Média & 20744 & 22139 \\
Maior & 474416 & 492111 \\
Menor & 56 & 56 \\
\hline Fonte: SPPC/MPS & & \\
Elaboração: autor & &
\end{tabular}

Apesar de as EFPCs atenderem um público reduzido, o total de ativos financeiros é expressivo. Em média, com base em valores deflacionados pelo IGP-DI, o total de ativos por EFPC foi de R\$2,1 bilhões em reais de 2011, sendo que para a maior delas o patrimônio ultrapassou $\mathrm{R} \$ 155$ bilhões em todos os anos do biênio. De modo alternativo, o patrimônio per capita por

\footnotetext{
${ }^{4}$ Dados obtidos de da Previdência Social (2012).
} 
participante e pensionista em reais de 2011 foi de R\$ 96 mil em 2010 e R\$ 102 mil em 2011. Isso demonstra o grande volume de recursos financeiros administrados pelas EFPCs.

Tabela 2: Distribuição das EFPC por Ativos Financeiros Valores em R\$ de 2011 Deflacionados pelo IGP-DI: 2010-2011

\begin{tabular}{|c|c|c|}
\hline Valor dos Ativos Financeiros & 2010 & 2011 \\
\hline 0 - R\$ 50 milhões & 31 & 31 \\
\hline $\mathrm{R} \$ 50$ milhões - $\mathrm{R} \$ 200$ milhões & 67 & 63 \\
\hline $\mathrm{R} \$ 200$ milhões - $\mathrm{R} \$ 500$ milhões & 62 & 60 \\
\hline R\$ 500 milhões - $\mathrm{R} \$ 750$ milhões & 27 & 22 \\
\hline R\$ 750 milhões - R\$ 1 bilhão & 22 & 21 \\
\hline R \$ 1 bilhão - R $\$ 2$ bilhões & 31 & 37 \\
\hline $\mathrm{R} \$ 2$ bilhões - $\mathrm{R} \$ 3$ bilhões & 8 & 9 \\
\hline $\mathrm{R} \$ 3$ bilhões - R $\$ 5$ bilhões & 14 & 13 \\
\hline$>\mathrm{R} \$ 5$ bilhões & 15 & 15 \\
\hline Total & 277 & 271 \\
\hline Média & 2117968990 & 2114355924 \\
\hline Maior & 165828506845 & 155635099742 \\
\hline Menor & 6706247 & 5446643 \\
\hline
\end{tabular}

No que tange à razão entre Despesa Administrativa e Investimentos das EFPCs, os valores apresentam grande dispersão. Pouco menos de $10 \%$ das EFPCs apresentam relação Despesa Administrativa Anual/Investimentos Totais inferior a $0,25 \%$. Por seu turno, a proporção daquelas com relação superior a $2 \%$ foi de $10,1 \%$ em 2010 e $12,5 \%$ em 2012. Dado o potencial desse tipo de despesa sobre a redução do patrimônio acumulado pelos participantes ao longo dos anos e o potencial de baixa das taxas de juros, faz-se essencial a busca de eficiência no custeio administrativo.

Tabela 3: Distribuição da Razão entre Despesa Administrativa/Investimentos por EFPC: 2010-2011

\begin{tabular}{lcc}
\hline Razão Despesa Administrativa/Investimento & 2010 & 2011 \\
\hline $0-0,25 \%$ & 23 & 25 \\
$0,25 \%-0,50 \%$ & 71 & 64 \\
$0,50 \%-0,75 \%$ & 57 & 59 \\
$0,75 \%-1,00 \%$ & 37 & 33 \\
$1,00 \%-1,50 \%$ & 45 & 38 \\
$1,50 \%-2,00 \%$ & 16 & 18 \\
$>2,00 \%$ & 28 & 34 \\
Total & 277 & 271 \\
Média & 1,07 & 1,15 \\
Maior & 9,88 & 17,07 \\
Menor & 0,07 & 0,06 \\
\hline
\end{tabular}

Fonte: SPPC/MPS

Elaboração: autor 
Apresentam-se na sequência um conjunto de estatísticas básicas que corroboram para o Brasil os resultados encontrados na revisão de literatura empírica de outras nações, qual seja, a despesa administrativa cresce com a quantidade de participantes e com o total de ativos administrados, mas de modo menos que proporcional. A seção 4 sofistica essa análise e contém confirmação dos resultados dos ganhos de escala por meio do uso das técnicas econométricas apropriadas.

A tabela abaixo mostra as correlações positivas entre a despesa administrativa com o total de participantes e investimentos, o que era de se esperar dado que o custo é uma função crescente do produto. O ponto seguinte consiste em observar se as estatísticas básicas apontariam para a existência de ganhos de escala para cada um dos produtos: público participante e total de investimentos. A correlação capaz de indicar esse fenômeno seria, de um lado, aquela entre o total de participantes e a despesa administrativa média por participantes, e, por outro lado, a correlação entre o total de investimentos e a proporção da despesa administrativa/investimentos. Ambas são negativas para o biênio conforme apresentada na tabela abaixo, o que implica redução do custo médio à medida que o produto aumenta.

Tabela 4: Quadro de Correlações Entre Variáveis

\begin{tabular}{lcc}
\hline & Participantes & Investimentos \\
\hline Desp. Adm & 0,81 & 0,88 \\
Desp. Adm/Part & $-0,14$ & N.A. \\
Desp. Adm/Invest & N.A. & $-0,10$ \\
\hline N. A.: Não se aplica & & \\
Fonte: SPPC/MPS & & \\
Elaboração: autor & &
\end{tabular}

Os gráficos apresentados permitem melhor interpretação dos resultados encontrados na tabela anterior. Com o intuito de facilitar a visualização, os dados se apresentam em escala logarítmica e mostram as relações entre os respectivos custos administrativos médios por produto e o total do produto tal como no formato convencional de uma curva de custo médio.

Nos dois casos, estimou-se curva de custo médio como uma equação do segundo grau em função do formato tradicional em U. Observa-se nas figuras 1 e 2 acima que a parábola ficou restrita a sua parte decrescente. Isso se constitui em indicador de economias de escala para todo o domínio da base de dados. Na hipótese de existência de uma escala ótima, era de se esperar que a parábola estimada alcançasse um ponto de mínimo e fosse crescente a partir de então como indicativo de deseconomias de escala caso o total de produtos ultrapassasse determinado valor.

\section{Modelo Teórico}

Nesta seção se apresenta um modelo teórico -desenvolvido orginalmente pelos autores deste artigo- para as economias de escala na previdência complementar brasileira. Assume-se que as EFPC oferecem dois produtos. Em primeiro lugar, tem como intuito acumular ativos financeiros para fazer jus ao pagamento de benefícios previdenciários. Por fim, devem atender ao seu público 
Relação Custo Médio por Participaxntes x Participantes. Escala Logarítm

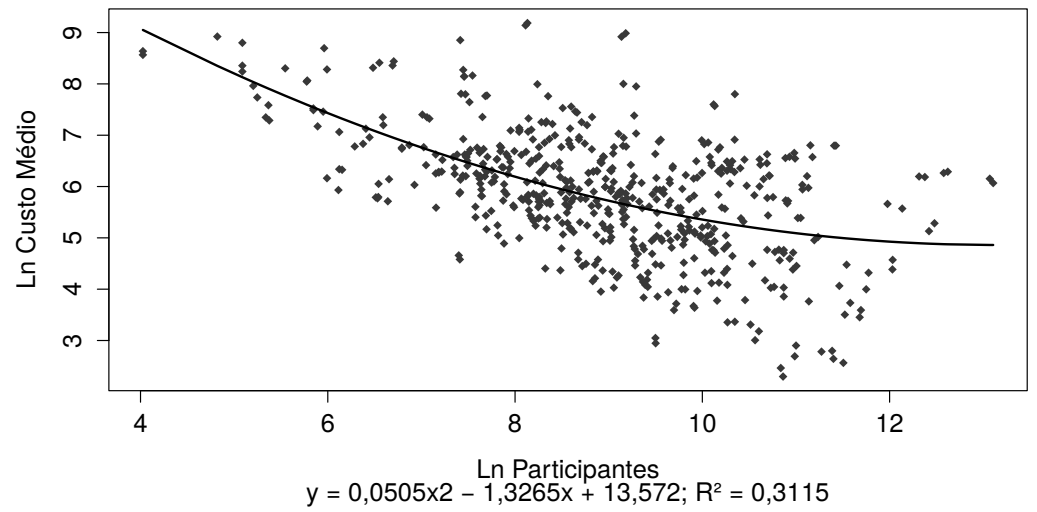

Fonte: SPPC/MPS

Elaboração: Autor

Figura 1: Relação Custo Médio por Participaxntes $\times$ Participantes. Escala Logarítmica

Relação Custo Médio por Participaxntes x Participantes. Escala Logarítm

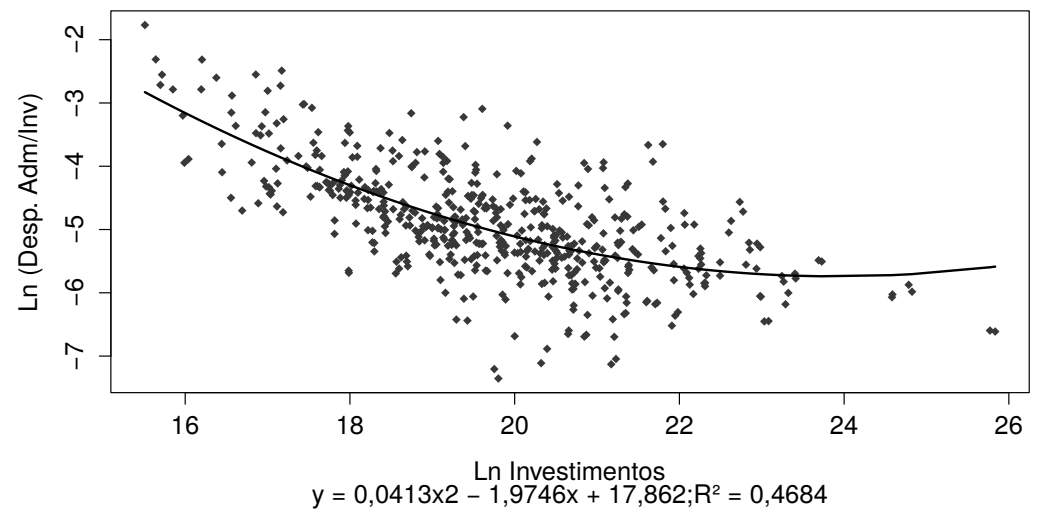

Fonte: SPPC/MPS

Elaboração: Autor

Figura 2: Relação entre Despesa Administrativa/Investimento $\times$ Investimento. Escala Logarítmica 
de participantes e pensionistas. Para tanto, necessitam utilizar um composto de serviços administrativos: pessoal próprio, rede de informática, equipamentos, consultores jurídicos e atuariais etc. A base teórica seria uma fronteira de possibilidade de produção (FPP) diferenciável com dois produtos -ativos financeiros acumulados e participantes- e um insumo de fatores administrativos na forma da equação (1) abaixo.

$$
F(W, Y, X)=0
$$

Em que $W$ é a quantidade de ativos financeiros, $Y$ seriam os participantes e pensionistas e $X$ os insumos administrativos.

Ponto relevante em relação à variável $Y$ é a diferença de custo para uma EFPC entre um participante ativo e outro aposentado ou pensionista. Em princípio, os participantes em gozo de benefício trazem à EFPC um custo administrativo superior em função da maior incidência de demandas judiciais, rede de atendimento, processamento e manutenção de benefícios etc ${ }^{5}$. Desse modo, a variável $Y$ pode ser entendida como uma função diferenciável de participantes ativos, de um lado, e de aposentados e pensionistas, de outro lado, tal como descrito na equação (2).

$$
Y=g(A t, A S)
$$

Onde $A t$ é a quantidade de participantes ativos e As é a quantidade de participantes assistidos, ou seja, aposentados e pensionistas. Supõe-se também que em função dos diferentes impactos sobre a necessidade de serviços de atendimento que:

$$
\frac{\partial \ln Y}{\partial \ln A s} \geq f r a c \partial \ln Y \partial \ln A t
$$

De 3 admite-se o uso de escalas de equivalência entre os dois grupos que compõem o público alvo da previdência complementar de modo que seja possível tratar o todo não somente como a soma linear não ponderada das partes, ou seja, é factível a existência de funções em que $Y \neq A t+A s$. Já houve uso dessa técnica de agregação em outras oportunidades. Por exemplo, Scholz et al. (2006) agregam uma família como $(A+0,7 C)^{0,7}$, em que $A$ é o número de adultos na família e $C$ equivale ao número de crianças. Para efeitos deste estudo não se faz necessário assumir alguma escala de equivalência em concreto. A hipótese (3) é suficiente. Dada essa suposição, a elasticidade do uso dos insumos administrativos em relação ao número de participantes assistidos é superior ou igual àquela dos ativos. Em termos matemáticos, pela regra da cadeia, a afirmação anterior se expressa na inequação (4).

$$
\frac{\partial \ln X}{\partial \ln Y} f r a c \partial \ln Y \partial \ln A s \geq \frac{\partial \ln X}{\partial \ln Y} f r a c \partial \ln Y \partial \ln A t
$$

O passo seguinte seria definir a elasticidade de escala para a FPP representada por (1). Por definição, economias de escala ocorrem quando o uso dos insumos cresce de modo menos que proporcional ao crescimento dos produtos. Na hipótese de insumos e produtos variarem na mesma proporção, há retornos constantes de escala. Por fim, deseconomias -retornos decrescentesde escala se observam caso os insumos precisem crescer de modo mais que

\footnotetext{
${ }^{5}$ Essa hipótese é corroborada na seção seguinte.
} 
proporcional aos produtos. Em termos matemáticos, a elasticidade de escala pode ser definida de modo análogo ao estabelecido em Coelli et al. (2005):

$$
\epsilon=\frac{\partial \ln X}{\partial \ln W}+\frac{\partial \ln X}{\partial \ln Y}
$$

Em que $\epsilon$ é a elasticidade de escala. A interpretação econômica da equação (5) reside no fato de mensurar o impacto de um aumento proporcional e simultâneo dos produtos $W$ e $Y$ sobre o uso, em termos também proporcionais, do insumo $X$. De (5), o valor de corte 1 define o comportamento das economias de escala. Verificam-se economias de escala caso a referida soma seja inferior à unidade, retornos constantes se a elasticidade se iguala a um e, por fim, deseconomias de escala para somatório superior ao valor unitário.

A implicação prática da hipótese (3) e da definição (5) é que o valor da elasticidade de escala varia em função da categoria de participante que sofre incremento. Os ganhos de escala são superiores naqueles EFPC com maior participação de participantes ativos. Em outras palavras, suponha duas EFPC idênticas em um momento inicial. Em um momento posterior, ambas apresentam igual crescimento na quantidade total de participantes. Porém em uma delas, o aumento foi maior para os participantes ativos e na outra para os assistidos. Nessas circunstâncias, as elasticidades de escala são distintas apesar do mesmo incremento no total de participantes. A EFPC cujo crescimento da quantidade de participantes se enviesou para aqueles em gozo de benefício apesentaria elasticidade de escala superior à outra EFPC em que o aumento de participantes foi enviesado para os ativos. Em síntese, EFPC com massa de participantes mais envelhecida tende a apresentar elasticidade de escala superior.

Na sequência, apresenta-se um exemplo concreto de modo a ilustrar a exposição mais geral acima. Suponha FPP representada pela equação (6):

$$
X=W^{\alpha}+(A s+\theta A t)^{\beta}
$$

Em que $\alpha>1, \beta>1$ e $0<\theta<1$. Essa FPP apresenta as características descritas pelas equações (3) e (4): há dois produtos -ativos financeiros e participantes-, sendo o último não representado por uma soma linear das partes. Demonstrar-se-á, na formulação algébrica da equação (6), que o impacto sobre a elasticidade do uso dos insumos de um aumento na quantidade de inativos supera aquele do incremento de participantes ativos.

Sejam $\epsilon_{A s}$ e $\epsilon_{A t}$ a elasticidade do uso dos insumos em relação aos participantes em gozo de benefício e ativos respectivamente. Nesse sentido,

$$
\epsilon_{A s}=\frac{\partial X}{\partial A s} \frac{A s}{X}=\beta(A s+\theta A t)^{\beta-1}\left(\frac{A s}{X}\right)
$$

$\mathrm{e}$

$$
\epsilon_{A t}=\frac{\partial X}{\partial A t} \frac{A t}{X}=\beta \theta(A s+\theta A t)^{\beta-1}\left(\frac{A t}{X}\right)
$$

Desse modo, a elasticidade do uso dos insumos em relação ao total de participantes é dada pela soma de (7) e (8) e se iguala a:

$$
\epsilon_{A s}+\epsilon_{A t}=\frac{\beta(A s+\theta A t)^{\beta-1}}{X}(A s+\theta A t)=\frac{\beta(A s+\theta A t)^{\beta}}{X}
$$


Cabe agora mostrar que o impacto sobre a elasticidade expressa em (9) do aumento de As supera o de $A t$, ou seja:

$$
\frac{\partial\left(\epsilon_{A s}+\epsilon_{A t}\right)}{\partial A s}>\frac{\partial\left(\epsilon_{A s}+\epsilon_{A t}\right)}{\partial A t}
$$

De fato,

$$
\frac{\partial\left(\epsilon_{A s}+\epsilon_{A t}\right)}{\partial A s}=\frac{\beta^{2}(A s+\theta A t)^{\beta-1}\left[X-(A s+\theta A t)^{\beta}\right]}{X^{2}}
$$

Por sua vez,

$$
\frac{\partial\left(\epsilon_{A s}+\epsilon_{A t}\right)}{\partial A t}=\frac{\theta \beta^{2}(A s+\theta A t)^{\beta-1}\left[X-(A s+\theta A t)^{\beta}\right]}{X^{2}}
$$

Substituindo o valor de X dado pela equação (6) em (10), tem-se que:

$$
\frac{\partial\left(\epsilon_{A s}+\epsilon_{A t}\right)}{\partial A s}=\frac{\beta^{2}(A s+\theta A t)^{\beta-1}}{W} X^{2}
$$

Ao se fazer o mesmo processo de substituição da equação (6) em (11), chega-se a:

$$
\frac{\partial\left(\epsilon_{A s}+\epsilon_{A t}\right)}{\partial A t}=\frac{\theta \beta^{2}(A s+\theta A t)^{\beta-1}}{W} X^{2}
$$

Resta ver se a derivada parcial expressa em (12) supera aquela apresentada em (13), isto é, se a elasticidade do uso dos insumos administrativos apresenta maior sensibilidade em relação ao número de participantes assistidos comparativamente aos participantes ativos. De fato essa condição prevalece, dado que $0<\theta<1$.

\section{Resultados empíricos}

Supôs-se nesta seção de teste econométrico uma função de custo com dois produtos, quais sejam, o total de participantes e de ativos administrados, tal como estabelecido na equação (??) em que o subescrito $i$ se refere à EFPC e $t$ ao tempo. Seguindo a tradição dos trabalhos empíricos descritos na revisão da literatura internacional sobre o tema apresentada na introdução deste artigo, adicionaram-se variáveis de controle as quais estão descritas no decorrer desta seção e são representadas por $X$ em (14).

$$
\ln C_{i t}=\alpha_{0}+\alpha_{1} \ln P A R T_{i t}+\alpha_{2} \ln \text { Ativos }_{i t}+\alpha_{3} X_{i t}+\epsilon_{i t}
$$

Para efeitos da equação (14), a variável dependente é a despesa administrativa, as variáveis independentes são os dois produtos (participantes e ativos administrados) e as variáveis de controle, quais sejam, relação entre beneficiários e participantes ativos, dummy patrocinador privado, dummy instituidor ${ }^{6}$, quantidade de planos da EFPC e quantidade de patrocinadores da EFPC.

De acordo com a equação acima, vale lembrar que a existência de economias de escala se verifica na hipótese em que a soma dos coeficientes $\alpha_{1}$ e

\footnotetext{
${ }^{6} \mathrm{~A}$ dummy referente ao patrocínio privado assume valor 1 nessa forma de patrocínio e 0 em caso contrário. Por seu turno, a dummy referente a Instituidores assume valor 1 caso seja dessa modalidade e 0 em caso contrário.
} 
$\alpha_{2}$ seja inferior à unidade. A elasticidade menor que um indica que o custo administrativo cresce de modo menos que proporcional em relação à variável quantidade de participantes e pensionistas, de um lado, e ao total de investimentos da EFPC, de outro lado.

Assumir a existência de dois produtos traz como vantagens a identificação do efeito marginal de cada variável e a redução da probabilidade de ocorrência de viés de omissão de variável. Como é de se esperar que entidades com maior número de participantes possuam mais ativos financeiros, a omissão de uma dessas variáveis tende a sobre-estimar o impacto marginal da variável independente utilizada sobre o custo administrativo.

Em relação às demais variáveis de controle ${ }^{7}$, supõe-se também que o custo administrativo deve ser superior naquelas entidades que contam com maior número de aposentados e pensionistas em relação ao total de participantes em atividade tal como exposto na seção referente ao modelo teórico. Isso acontece em decorrência da maior necessidade de rede de atendimento, demandas judiciais, processamento de benefícios etc. Tal como exposto no modelo teórico, pode-se interpretar a elevação da participação dos aposentados e pensionistas como perdas incorridas nas economias de escala. De modo alternativo, caso se considerem participantes ativos como um produto potencialmente distinto dos participantes assistidos, essa variável também pode ser interpretada como um indicador de economias de escopo ${ }^{8}$. Nessa última interpretação, a elasticidade inferior a um seria indicador de ganhos de escopo. Para tanto, adicionou-se às variáveis de controle o logaritmo natural da razão de aposentados e pensionistas sobre o total de participantes ativos.

Procurou-se também investigar se as EFPC públicas teriam custo administrativo superior às privadas e aos instituidores. Nesse sentido, acrescentaramse duas dummies referentes àquelas formas de patrocínio.

Por fim, como forma de averiguar a existência de economias de escopo no setor - se é mais econômico que uma mesma EFPC ofereça planos previdenciários para empresas distintas do que cada empresa instituir separadamente sua própria EFPC e seu plano de benefício, inseriram-se variáveis referentes aos valores absolutos da quantidade de planos e da quantidade de patrocinadores por EFPC. Caso os coeficientes dessas semielasticidades não sejam estatisticamente distintos de zero, assume-se então a ocorrência de economias de escopo porque o oferecimento de um plano a mais ou a adesão de uma nova patrocinadora não afetaria o custo administrativo da EFPC. É importante observar que na hipótese da existência de ganhos de escopo, o aumento do custo seria reflexo da elevação da quantidade de participantes e de ativos administrados decorrentes da adesão de novo patrocinador, e não da disponibilização de outro plano de benefícios em si.

Os dados foram estruturados na forma de um painel não balanceado para os anos de 2010 e 2011 e se referem a 283 EFPCs. Rodaram-se modelos econométricos em painel tanto com efeitos aleatórios quanto com fixos, assim como

\footnotetext{
${ }^{7}$ Rodaram-se modelos sem as demais variáveis de controle que mostraram resultados também favoráveis à existência de economias de escala, porém com elasticidade superior para investimentos e inferior para participantes.

${ }^{8}$ Apesar de teoricamente possível, a interpretação dos participantes ativos como um produto distinto dos assistidos parece implicar grau especialização pouco intuitivo porque a finalidade de um fundo previdenciário é acumular recursos na fase ativa para pagamento de aposentadorias e pensões na época de gozo de benefício. Em termos análogos seria como separar em um restaurante o serviço de refeição do aluguel de talheres ou em educação se segmentar o serviço de lecionar da correção de provas.
} 
se estimaram fronteiras estocásticas (FE) para a função custo. As FE consideram três formatos distintos para a função custo: (i) na forma da equação (14) em que as variáveis quantidade de planos e de patrocinadores aparecem em valor absoluto; (ii) uma transformação em (14) para que essas duas últimas variáveis fossem consideradas em escala logarítmica, tornando-se mais próxima de uma Cobb-Douglas e da análise usual da FE e (iii) tal como uma translog de modo a capturar as diversas interações entre as variáveis ${ }^{9}$. Em termos concretos, os resultados encontrados nas diversas modelagens se complementam, o que demonstra sua robustez a distintas técnicas estatísticas e formas funcionais. Todos apresentaram ganhos expressivos de escala, sendo mais significativos no modelo de painel com efeitos fixos.

Em relação à aplicação da econometria em dados de painel para o presente trabalho, existe um conjunto de motivações para o uso dos efeitos aleatórios. Em primeiro lugar, há características das EFPC que são invariantes no tempo, mas que tendem a influenciar o custo administrativo e que necessitam de investigação. Mais especificamente, se há diferença de custos entre a administração pública e privada. Por exemplo, a Lei Complementar 108/2001 traz exigências que somente se aplicam às EFPCs de patrocinadores públicos. Além disso, os instituidores formam um grupo distinto das demais EFPCs. Em termos intuitivos, essas características institucionais e invariantes no tempo parecem ser mais relevantes para determinação do custo administrativo do que o perfil estritamente individual de uma EFPC. Segundo, como não foi possível identificar variação na quantidade de planos e patrocinadores no biênio, não seria possível fazer o teste de economias de escopo com efeitos fixos. Em terceiro lugar, não há interesse especifico em analisar somente o impacto das variáveis que mudam ao longo do tempo; até porque o intervalo temporal disponível na base dados é de apenas dois anos.

Naturalmente que se faz necessário contrastar os resultados do modelo de efeitos aleatórios com o de efeitos fixos como forma de averiguar o impacto do perfil individual sobre o institucional. A capacidade de filtrar o resultado das características individuais não-observáveis é uma vantagem comumente arrolada para a econometria dos dados em painel com efeitos fixos. Apesar da preferência conceitual pelo modelo com efeitos aleatórios por causa da possibilidade da estimação do impacto marginal de variáveis temporalmente invariantes, o modelo com efeitos fixos estimou ganhos de escala ainda mais expressivos. Isso indica que nesse caso em concreto - ainda que de uma perspectiva normativa, e não técnica - o conservadorismo seria uma razão de foco no modelo de efeitos aleatórios como forma de evitar conclusões demasiado otimistas acerca do potencial dos ganhos de escala.

Não se apresenta o modelo com efeitos fixos no tempo - dummies por ano-, dado que o teste das estatísticas $F$ e $t$ para esse tipo de efeito indicaram probabilidade de $18,2 \%$ para não rejeição da hipótese de dummy temporal igual a zero ${ }^{10}$. As evidências estatísticas se mostraram favoráveis aos efeitos fixos dado que o teste de Hausman apresentou $\chi^{2}$ de 62,5. Os resultados encontrados estão listados na tabela abaixo.

\footnotetext{
${ }^{9}$ Vale notar que em função da impossibilidade de se rodar FE no formato translog para painel não balanceado de um biênio, essa última estimativa reduziu a análise somente para aquelas EFPC que apresentavam dados para todos os anos. Desse modo, o total de EPFCs no modelo de FE translog se reduziu de 283 para 265.

${ }^{10}$ Como há somente dois anos neste painel, as estatísticas F e t coincidem em seus valores.
} 
Tabela 5: Estimativas da regressão das despesas administrativas em relação às características das EFPC. Erro padrão entre parênteses

\begin{tabular}{|c|c|c|c|c|c|}
\hline & \multicolumn{5}{|c|}{ Variável dependente $=\ln ($ Despesa Administrativa $)$} \\
\hline & Modelo 1 & Modelo 2 & Modelo 3 & Modelo 4 & Modelo 5 \\
\hline $\begin{array}{l}\text { Participantes e pensio- } \\
\text { nistas }(\ln )\end{array}$ & $\begin{array}{l}0,205^{*} \\
(0,030)\end{array}$ & $\begin{array}{c}0,174^{*} \\
(0,040)\end{array}$ & $\begin{array}{l}-0,077^{* * *} \\
(0,095)\end{array}$ & $\begin{array}{l}0,179^{*} \\
(0,038)\end{array}$ & $\begin{array}{l}0,177^{*} \\
(0,039)\end{array}$ \\
\hline $\begin{array}{l}\text { Ativos Financeiros (ln } \\
\text { em R\$ deflacionados } \\
\text { pelo IGP-DI) }\end{array}$ & $\begin{array}{l}0,441^{*} \\
(0,029)\end{array}$ & $\begin{array}{r}0,435^{*} \\
(0,038)\end{array}$ & $\begin{array}{l}0,198^{*} \\
(0,100)\end{array}$ & $\begin{array}{l}0,436^{*} \\
(0,037)\end{array}$ & $\begin{array}{l}0,437^{*} \\
(0,037)\end{array}$ \\
\hline $\begin{array}{l}\text { Relação Beneficiá- } \\
\text { rios/Participantes } \\
\text { Ativos }(\ln )\end{array}$ & $\begin{array}{l}0,131^{* *} \\
(0,017)\end{array}$ & $\begin{array}{l}0,108^{* *} \\
(0,022)\end{array}$ & $\begin{array}{r}-0,058 \\
(0,059)\end{array}$ & $\begin{array}{l}0,111^{* *} \\
(0,021)\end{array}$ & $\begin{array}{l}0,110^{* *} \\
(0,021)\end{array}$ \\
\hline $\begin{array}{l}\text { Dummy Patrocinador } \\
\text { Privado }\end{array}$ & $\begin{array}{l}-0,616^{* *} \\
(0,056)\end{array}$ & $\begin{array}{c}-0,665^{* *} \\
(0,080)\end{array}$ & N.A. & $\begin{array}{c}-0,659^{* *} \\
(0,076)\end{array}$ & $\begin{array}{c}-0,659^{* *} \\
(0,076)\end{array}$ \\
\hline Dummy Instituidor & $\begin{array}{r}-0,218 \\
(0,134)\end{array}$ & $\begin{array}{r}-0,326 \\
(0,188)\end{array}$ & N.A. & $\begin{array}{r}-0,310 \\
(0,179)\end{array}$ & $\begin{array}{c}-0,308 \\
(0,179)\end{array}$ \\
\hline $\begin{array}{l}\text { Quantidade de Planos } \\
\text { da EFPC }\end{array}$ & $\begin{array}{l}0,004 \\
(0,003)\end{array}$ & $\begin{array}{c}0,005 \\
(0,004)\end{array}$ & N.A. & $\begin{array}{l}0,005 \\
(0,004)\end{array}$ & $\begin{array}{l}0,005 \\
(0,004)\end{array}$ \\
\hline $\begin{array}{l}\text { Quantidade de Patroci- } \\
\text { nadores da EFPC }\end{array}$ & $\begin{array}{l}0,003 \\
(0,002)\end{array}$ & $\begin{array}{l}0,003 \\
(0,002)\end{array}$ & N.A. & $\begin{array}{l}0,003 \\
(0,002)\end{array}$ & $\begin{array}{l}0,003 \\
(0,002)\end{array}$ \\
\hline Constante & $\begin{array}{l}4,943^{* *} \\
(0,393)\end{array}$ & $\begin{array}{l}5,331^{* *} \\
(0,533)\end{array}$ & $\begin{array}{r}11,479^{* *} \\
(1,585)\end{array}$ & $\begin{array}{l}2,579 \\
(10,699)\end{array}$ & $\begin{array}{l}2,710^{* * *} \\
(1,282)\end{array}$ \\
\hline Número de EFPC & 283 & 283 & 283 & 283 & 283 \\
\hline$R^{2}$ & $0,8346^{a}$ & $0,8336^{b}$ & $0,525^{b}$ & N.A. & N.A. \\
\hline $\begin{array}{l}\text { Notas: } \\
\text { Modelo 1: Mínimos quac } \\
\text { Modelo 2: Regressão GL } \\
\text { Modelo 3: Regressão em } \\
\text { Modelo 4: Fronteira esto } \\
\text { Modelo 5: Fronteira esto } \\
a: R^{2} \text { ajustado é igual a } 0 \\
b: R^{2} \text { geral (overall) } \\
{ }^{*} \text {.A.: Não se aplica } \\
{ }^{*} \text { :Coeficiente estatisticam } \\
{ }^{* *}: \text { Coeficiente estatistica } \\
{ }_{* * *}\end{array}$ & $\begin{array}{l}\text { ados ordina } \\
\text { em painel c } \\
\text { ainel com e } \\
\text { ástica para } \\
\text { ástica para } \\
325\end{array}$ & $\begin{array}{l}\text { ios } \\
\text { m efeitos ale } \\
\text { eitos fixos } \\
\text { Isto com efic } \\
\text { sto com efic }\end{array}$ & $\begin{array}{l}\text { órios } \\
\text { ncia invariar } \\
\text { ncia variant }\end{array}$ & $\begin{array}{l}\text { no tempo } \\
\text { o tempo }\end{array}$ & \\
\hline
\end{tabular}

À primeira vista, observam-se resultados qualitativamente bastante similares seja na regressão de mínimos quadrados ordinários (MQO) - modelo 1 da tabela acima - , seja na de painel em GLS com efeitos aleatórios - modelo 2. Entretanto, os testes estatísticos indicarem a existência de ganhos no modelo de painel com efeitos aleatórios em relação ao de mínimos quadrados. O estatística de Breusch-Pagan dos multiplicadores de Lagrange para efeitos aleatórios apresentou $\chi^{2}$ de 212,5 . Por essa razão, a análise de resultados se fará com base no modelo de painel.

As economias de escala em relação à quantidade de participantes e pensionistas se mostraram expressivas no caso brasileiro. A elasticidade foi estimada em 0,17 no painel de efeitos aleatórios. Nos demais estudos apresentados na revisão de literatura, a menor elasticidade para o número de participantes foi de 0,4 para o caso australiano reportada em Bateman \& Mitchell (2004). Esse fato indica o maior potencial de ganhos de escala em relação à quantidade de participantes no Brasil comparativamente ao resto do mundo. Por seu turno, a economia de escala referente aos ativos financeiros - cuja elasticidade está em 0,44 no painel de efeitos aleatórios — encontra-se em linha com o valor en- 
contrado na literatura internacional. No modelo de efeitos fixos, a evidência favorável aos ganhos de escala - tanto em relação ao número de participantes quanto relativo ao investimento total - foi mais expressiva com valor das elasticidades inferiores ao dos efeitos aleatórios.

Tal como previsto no modelo teórico, o aumento da participação de beneficiários no total de participantes contribui para a elevação do custo administrativo. De fato, em todos as especificações, exceto no modelo 3, essa variável se mostrou estatisticamente diferente de zero no nível de $5 \%$.

Resultado também relevante foi o fato de o coeficiente para a dummy das EFPCs privadas se mostrar negativo e estatisticamente diferente de zero ao nível de 5\%. A partir de uma interpretação dos coeficientes desta dummy como redutor do valor da constante da equação, conclui-se que a EFPC privada apresenta constante $12 \%$ inferior à pública. Com base nos dados disponíveis e no resultado encontrado, conclui-se que as entidades públicas de previdência complementar são mais caras. Não é possível identificar sua causa. Pode ser decorrente tanto de ineficiência intrínseca quanto de legislação mais rígida que se aplica às EFPCs com esse perfil.

Essa dummy mostra o potencial de complementação dos modelos de efeitos fixos e aleatórios. Ainda que os efeitos fixos apontem para a relevância de características idiossincráticas das EFPC, os efeitos aleatórios mostram que uma dessas características é o fato de ter patrocínio público ou privado. Uma possível conclusão do modelo de efeito fixo sobre os custos da previdência complementar fechada brasileira seria uma estrutura fortemente determinada por elementos fixos, quase fixos ou afundados e de custo marginal insignificante à inclusão de novos participantes, mas levemente sensível aos valores investidos.

A predominância da idiossincrasia para determinação do custo leva ao questionamento acerca da influência da regulação sobre tal resultado. Uma hipótese seria o incentivo inadequado gerado pelos tetos às taxas de administração e carregamento estabelecidos na Resolução CGPC 29/2009. Com regulação baseada somente nesses limites superiores, pode ser que algumas EFPCs busquem elevar seu custeio próximo ao nível máximo autorizado pela norma, ou seja, atuem em busca do rent-seeking permitido pela legislação ao não repassar todo ganho de escala aos participantes. Outras, em função de transparência, assim como da atuação e fiscalização dos participantes podem repassar mais dos ganhos de escala a estes. Não é possível identificar o efeito rent-seeking com a base de dados disponível. Fica, entretanto, recomendação aos reguladores para a busca de exemplos de casos bem-sucedidos de baixo custo administrativo.

No que tange aos instituidores, sua dummy não se mostrou estatisticamente distinta de zero ao nível de 5\%. Portanto, não há como identificar diferenças em relação aos custos administrativos entre instituidores e patrocinadores públicos.

Por fim, a evidência de economias de escopo também se mostrou substancial. As semielasticidades da quantidade de planos e de patrocinadores ficaram com valor absoluto muito próximo a zero e também se mostraram estatisticamente insignificantes ao nível de 5\%. Em outras palavras, o impacto sobre o custo administrativo da criação de novo plano e da adesão de outro patrocinador é diminuto. Como usual em econometria, esses resultados são analisados ao se considerar todas as demais variáveis constantes. O que se afirma é que a mera adesão de nova patrocinadora ou a criação de novo plano terá im- 
pactos estatisticamente insignificantes sobre o custo, mas como naturalmente aumentarão os produtos oferecidos - participantes e ativos financeiros acumulados - o custo total se elevará. Entretanto, as estatísticas apresentadas anteriormente já se mostraram favoráveis à existência de economias de escala.

Como forma de se averiguar a robustez dos resultados a distintas especificações estatísticas, também os modelos 4 e 5 realizaram estimativas referentes a uma FE para custos. A diferença básica entre a econometria convencional e a FE é que enquanto a primeira estima o comportamento médio do grupo como um todo; a segunda traça o formato da curva das unidades - EFPC para o caso concreto deste artigo - mais eficientes.

Para se observar o quanto os resultados se modificam somente em decorrência da alteração da técnica para $\mathrm{FE}$, manteve-se a mesma especificação da equação (14) tal como utilizada nos modelo 1 (MQO) e 2 (painel com efeitos aleatórios).

A distribuição dos erros dos modelos 4 e 5 de FE é do tipo normal/normal truncada. A distinção entre esses dois modelos é que o quarto supõe eficiência invariante no tempo, enquanto o quinto assume evolução exponencial da eficiência. Esses dois modelos apresentam resultados bastante próximos entre si o que era esperado dado se tratar de painel com somente dois períodos, sendo, portanto, difícil constatar mudança no padrão de eficiência em tão curto intervalo temporal. Isso se comprova pelo fato de o parâmetro referente à evolução temporal da eficiência do modelo 5 não ser estatisticamente diferente de zero.

Ponto relevante na comparação dos modelos é a semelhança dos coeficientes de FE dos modelos 4 e 5 com o painel de efeitos aleatórios - modelo 2 - e o MQO - modelo 1, conforme se observa na tabela acima. Somente a constante da função de custos apresentou valor expressivamente distinto na comparação dos modelos de FE com os demais. Em outras palavras, o traçado da curva de custo é o mesmo em termos de suas derivadas parciais seja ao se considerar o perfil médio das EFPCs ou das unidades mais eficientes. O que a FE fez em relação aos modelos econométricos convencionais foi deslocar a curva de custo para um patamar inferior. Ou seja, o potencial de ganhos de escala se mostra muito similar seja na média do grupo como um todo ou nas unidades de maior eficiência. As diferenças das EFPC mais e menos eficientes não se explicam por causa da escala. Essa comparação de resultados demonstra a robustez do modelo a diferentes especificações.

Possível crítica aos modelos 4 e 5 de FE seria o fato de tratarem duas variáveis em seus valores absolutos, e não em escala logarítmica. São elas a quantidade de planos e de patrocinadores. De fato, esses dois modelos anteriores se desenvolveram com o intuito de averiguar a sensibilidade de resultados somente em função de mudança da técnica econométrica dos dados em painel para FE. De modo a tornar o tratamento mais próximo ao convencional em FE, os modelos 6 e 7 fazem uso de todas as variáveis em escala logarítmica -exceto naturalmente as dummies- conforme se observa na tabela abaixo. No mais, mantêm as mesmas características dos modelos 4 e 5, quais sejam, distribuição de erros do tipo normal/normal truncada, eficiência invariante no tempo para o modelo 6 e evolução exponencial da eficiência para o modelo 7 .

O fato de se modificar o formato da FE para uma função do tipo CobbDouglas não provocou alteração substancial nos resultados e suas interpretações qualitativas, exceto para a variável quantidade de planos, a qual passou a ser estatisticamente diferente de zero ao nível de 5\% de significância. Entretanto, como seu valor é bastante inferior à unidade, o aumento da quantidade 
Tabela 6: Estimativas de FE para a despesa administrativa em relação às características das EFPC para função do tipo Cobb-Douglas. Erro padrão entre parênteses

\begin{tabular}{|c|c|c|}
\hline & \multicolumn{2}{|c|}{ Variável dependente $=\ln ($ Despesa Administrativa $)$} \\
\hline & Modelo 6 & Modelo 7 \\
\hline Participantes e pensionistas (ln) & $\begin{array}{l}0,114^{*} \\
(0,040)\end{array}$ & $\begin{array}{l}0,112^{*} \\
(0,040)\end{array}$ \\
\hline $\begin{array}{l}\text { Ativos Financeiros (ln em } \mathrm{R} \$ \text { de- } \\
\text { flacionados pelo IGP-DI) }\end{array}$ & $\begin{array}{l}0,447^{*} \\
(0,037)\end{array}$ & $\begin{array}{l}0,449^{*} \\
(0,037)\end{array}$ \\
\hline $\begin{array}{l}\text { Relação Beneficiá- } \\
\text { rios/Participantes Ativos }(\ln )\end{array}$ & $\begin{array}{l}0,089^{*} \\
(0,021)\end{array}$ & $\begin{array}{l}0,088^{*} \\
(0,021)\end{array}$ \\
\hline Dummy Patrocinador Privado & $\begin{aligned}-0,693^{* *} \\
(0,078)\end{aligned}$ & $\begin{aligned}-0,694^{* *} \\
(0,078)\end{aligned}$ \\
\hline Dummy Instituidor & $\begin{array}{c}-0,306 \\
(0,178)\end{array}$ & $\begin{array}{c}-0,305 \\
(0,178)\end{array}$ \\
\hline $\begin{array}{l}\text { Quantidade de Planos da EFPC } \\
\text { (ln) }\end{array}$ & $\begin{array}{l}0,188^{*} \\
(0,045)\end{array}$ & $\begin{array}{l}0,188^{*} \\
(0,045)\end{array}$ \\
\hline $\begin{array}{l}\text { Quantidade de Patrocinadores } \\
\text { da EFCP }(\ln )\end{array}$ & $\begin{array}{r}0,066 \\
(0,035)\end{array}$ & $\begin{array}{r}0,066 \\
(0,034)\end{array}$ \\
\hline Constante & $\begin{array}{c}2,613 \\
(18,953)\end{array}$ & $\begin{array}{r}2,750 \\
(1,659)\end{array}$ \\
\hline Número de EFPC & 283 & 283 \\
\hline \multicolumn{3}{|c|}{$\begin{array}{l}\text { Notas: } \\
\text { Modelo 6: Fronteira estocástica para custo com eficiência invariante no tempo e } \\
\text { função do tipo Cobb-Douglas } \\
\text { Modelo 7: Fronteira estocástica para custo com eficiência variante no tempo e função } \\
\text { do tipo Cobb-Douglas } \\
{ }^{*} \text { :Coeficiente estatisticamente distinto de } 0 \text { e } 1 \text { ao nível de } 5 \% \text {. } \\
* * \text { Coeficiente estatisticamente significante ao nível de } 5 \% \text {. }\end{array}$} \\
\hline
\end{tabular}

de planos eleva menos que proporcionalmente a despesa administrativa, resultado que indica a existência de economias de escopo.

Mantêm-se a conclusão de que a grande mudança ocasionada pela adoção da FE foi a queda do valor da constante. Em outras palavras, as derivadas parciais são basicamente as mesmas do modelo da econometria de MQO e de painel com efeitos aleatórios. Os mais eficientes têm tão somente uma curva de custo mais baixa que a média, mas de formato similar em relação a suas derivadas parciais.

Tal como nos modelos anteriores de FE, o parâmetro referente à evolução temporal da eficiência não se mostrou estatisticamente distinto do valor nulo ao nível de 5\%. Resultado esperado dado se tratar de um painel para um biênio.

Como forma adicional de se flexibilizar a análise e testar a robustez da hipótese das economias de escala na previdência complementar fechada brasileira a outros formatos funcionais, apresentam-se adiante estimativas de elasticidades para uma função de custo do tipo logarítmica transcendental, também conhecida como translog ${ }^{11}$.A principal diferença entre este formato e aquele proposto em (14) é que a translog captura o impacto das interações — realizadas de modo um a um- entre as variáveis independentes. Para o caso em análise neste artigo, a equação (14) se transforma em:

\footnotetext{
${ }^{11}$ Os trabalhos empíricos anteriores sobre o tema não realizaram estudo com formato funcional flexível da translog, de modo que se trata de outra inovação realizada nesse estudo.
} 


$$
\ln C_{i t}=\alpha_{0}+\sum_{n=1}^{7} \alpha_{n} W_{n i t}+\frac{1}{2} \sum_{n=1}^{7} \sum_{m=1}^{7} \alpha_{n m} W_{n i t} W_{m i t}+\epsilon_{i t}
$$

Em que $W_{n}$ é o logaritmo natural de cada uma das variáveis independentes da equação (14) quando esta variável não for dummy. Caso essa variável $W_{n}$ seja do tipo dummy, então $W_{n}$ é seu próprio valor. Observa-se também que não há sentido em se estimar o parâmetro $\alpha_{n n}$ na hipótese de a variável $n$ ser uma dummy, isso porque a multiplicação da dummy por ela mesma é a própria variável em questão. O expressivo número de interações entre as variáveis independentes faz com que o número de parâmetros a se estimar em (15) seja muito elevado. Por essa razão, o resultado dessa regressão é apresentado como apêndice ao final do texto.

Por decorrência do formato da translog, o valor das elasticidades difere em cada ponto observado dos dados. Como forma de suplantar essa dificuldade e apresentar uma estatística síntese dos resultados, é usual o cálculo da elasticidade no valor médio dos dados tal como sugerido em Greene (2012) e Coelli et al. (2005). Por meio dessa técnica, a elasticidade do custo administrativo em relação aos ativos financeiros alcançou o valor de 0,541 e em relação ao total de participantes e pensionistas atingiu a quantia de 0,069. Apesar da diferença para os valores observados entres os modelos 1 e 7 , os resultados qualitativos permanecem os mesmos e apontam para a existência de ganhos de escala. A elasticidade dos ativos financeiros cresceu de 0,44 para 0,54 na FE translog em relação aos demais modelos; entretanto, a elasticidade em relação ao número de participantes caiu de um valor entre 0,11 e 0,18 para 0,07. Em outras palavras, a elasticidade de escala que representa a soma das duas derivadas parciais anteriores ficou em 0,61 no modelo de FE translog, valor muito próximo àqueles encontros nos modelos de 1 a 7 que ficaram entre 0,56 e 0,64 . Em suma, os resultados referentes às economias de escala na previdência complementar brasileira se mostram robustos a diversos formatos funcionais e técnicas estatísticas ${ }^{12}$.

\section{Implicações normativas}

No que se refere às implicações normativas dos resultados encontrados, a evidência favorável aos ganhos de escala demonstra a dificuldade que uma empresa de menor porte teria para criação da sua EFPC. A princípio, isso pode representar empecilho à expansão da previdência complementar. Entretanto, os ganhos de escopo indicam a viabilidade da política de fomento ao setor.

Por um lado, a existência de poucas EFPCs permite melhor aproveitamento da escala e redução do custo administrativo médio por participante o que implica que a concentração das EFPCs traria escala mais eficiente de operação. Por outro lado, o baixo custo marginal da criação de um novo plano

\footnotetext{
${ }^{12}$ Possível questionamento às evidências favoráveis aos ganhos de escala seria o porquê de o setor não já tê-los aproveitado e passado por um processo de consolidação de modo a formar um monopólio natural. Há um conjunto de contra-argumentos. Do ponto de vista institucional, as EFPC não possuem fins lucrativos. Ademais, a consolidação implica perdas de autonomia de gestão e definição do plano por parte dos participantes e patrocinadores. Na perspectiva normativa, não parece ser interessante transformar o setor em monopólio e abolir possível competição. Por fim, sob a ótica empírica, apesar de a evidência internacional favorável à existência de ganhos de escala no setor não se observou tamanha consolidação no resto do mundo.
} 
de benefícios ou da adesão de um patrocinador a uma EFPC já existente abre caminho para que a previdência complementar se estenda a empresas de menor porte.

A política prescrita seria o estimulo à adesão de empresas menores às EFPCs de firmas de grande porte. Recomenda-se a livre associação entre diversas empresas para que criem ou participem de um fundo pré-existente. $\mathrm{O}$ benefício para o próprio setor seria duplo. Primeiramente, as economias de escala decorreriam do grande porte de operação das entidades fechadas. Em segundo lugar, a competição entre grandes EFPCs por patrocinadoras pequenas permitiria o repasse dos ganhos de escala aos empregados dessas firmas. Ambiente não competitivo pode simplesmente fazer com que as grandes EFPCs absorvam a maior ganho de escala para si e pouco repassem aos outros patrocinadores e participantes. A competição é ampliada ao se considerar a alternativa dos planos das entidades abertas oferecidos por bancos e seguradoras. Por analogia, trata-se de prescrição de estrutura semelhante àquela observada no setor de telefonia e companhias aéreas. Fonte adicional de redução de custos na gestão previdenciária seria a gestão compartilhada de ativos e atividades administrativas.

No que se refere à expansão da previdência complementar para servidores públicos, a evidência favorável às economias de escala e escopo sugere que a União e governos de grandes Estados como Rio de Janeiro e São Paulo, por exemplo, podem criar EFPCs multipatrocinadas como instrumento para que a previdência complementar alcance servidores de Municípios e Estados de menor porte. O benefício social da expansão da previdência privada seria a menor necessidade de provisão governamental da renda auferida pelos cidadãos em idade avançada com o respectivo alívio da carga tributária e a possibilidade de alocação de recursos públicos em outras áreas prioritárias. Também na análise intrafamiliar, reduz-se o montante de recursos que os filhos destinam ao sustento dos seus pais.

Ponto normativo de possível discussão é o estabelecimento de número mínimo de participantes para funcionamento de uma EFPC. No marco jurídico vigente no Brasil, a exigência relativa a esse quesito se aplica apenas aos instituidores cuja entidade- de acordo com o art. 17 da Resolução CGPC 29/2009deve ter pelo menos quinhentos participantes no momento da sua criação. A EFPC não é obrigada a fechar caso seus participantes fiquem aquém dos quinhentos ao longo do tempo.

Em defesa do estabelecimento de quantitativo mínimo, além da escala, há a diluição de riscos entre os participantes. Especialmente ao se tratar das incertezas relacionadas à concessão de aposentadorias por invalidez e pensão por morte. Para citar um exemplo radical, uma EFPC com somente cinquenta participantes pode ter sua solvência comprometida caso um acidente venha a vitimar cinco deles. Analogamente, pode incorrer em provisão desnecessária de recursos caso seus participantes não se invalidem. De modo geral, pela lei dos grandes números, é necessário grupo maior de participantes para a convergência entre o valor esperado e a verdadeira média. Do ponto de vista contrário ao estabelecimento de mínimos, encontra-se o argumento que essa imposição governamental restringe a liberdade de escolha das pessoas físicas e jurídicas. Dentro dessa linha de raciocínio, caberia aos indivíduos - e não ao setor público de modo paternalista - definir o que é melhor para eles. Essas teses e antíteses deixam o debate ainda em aberto. Uma possível síntese dessas duas visões seria o regulador esclarecer aos participantes e patrocinadores so- 
bre os custos de entidades com poucos membros sem que isso se configurasse como imposição.

Vale notar que a existência de EFPC de porte expressivo pode gerar problemas do estilo "grande demais para falhar" usualmente aplicado ao setor bancário, o qual justifica repasse de recursos arrecadados de toda a sociedade para benefício de um setor específico quando esse passa por dificuldades. Apesar de não haver forma de eliminar esse risco -a própria crise financeira de 2008 é um exemplo concreto desse fato- há instrumentos para minimizá-lo por meio de regulação e estrutura de governança apropriadas. Na visão dos autores, as leis complementares 108 e 109/2001 possuem determinações para redução dos riscos de governança.

Além dos pontos anteriormente abordados, é natural que a opção por parte de uma pequena firma ou Município quanto à adesão à previdência complementar gerido por uma empresa ou ente maior vá além das questões meramente de custo. Aos ganhos de escala e escopo devem se contrapor a perda de autonomia na gestão previdenciária e a dificuldade em se definir plano mais adequado ao que desejam seus funcionários e a própria firma.

\section{Conclusão}

O presente artigo identificou a existência de economias de escala e escopo na previdência complementar brasileira a partir de amplo conjunto de testes econométricos e estatísticas descritivas.

A preocupação com o tema cresce em um momento de queda nas taxas de juros. Dado que a forma tradicional de obtenção de rendimento nos regimes capitalizados de previdência tem sua magnitude reduzida, faz-se natural o foco na eficiência como forma de redução dos custos previdenciários. A forma investigada acerca do potencial ganho de eficiência foram as economias de escala e escopo. Enquanto a primeira reflete reduções dos custos médios à medida que os produtos aumentam, a segunda se refere à redução dos custos quando produtos distintos são produzidos por uma mesma unidade econômica comparativamente ao caso em que cada produto é ofertado somente uma firma. Dado que os produtos no caso em análise são o público coberto pela EFPC e o total de ativos investidos, as economias de escala se verificam dado que o custo total cresce menos que proporcionalmente aos produtos, enquanto as economias de escopo refletem o baixo impacto sobre o custo administrativo tanto do oferecimento de um plano de benefícios adicional quanto da adesão de uma nova patrocinadora à EFPC.

A revisão de literatura apresentou vários estudos que apontaram para a existência de economias de escala na previdência complementar em outros países. Em comum, as estimativas econométricas para as funções de custo identificaram como produtos desse setor o total de participantes e pensionistas cobertos pela EFPC e o total de investimentos.

Essa perspectiva foi replicada tanto no modelo teórico quanto nos testes econométricos realizados por esse artigo. A econometria se mostrou robusta o suficiente de modo a corroborar a hipótese acerca da existência de economias de escala e escopo para previdência complementar brasileira. Tanto as estatísticas descritivas como todos os testes econométricos em que se alteraram sejam as técnicas utilizadas seja o formato funcional confirmaram a existência de economias de escala. 
A implicação normativa desses resultados é que a exploração dos ganhos de escala e escopo pode se constituir em forma eficiente de incremento da cobertura previdenciária complementar no Brasil. Fato relevante em um contexto em que a provisão pública de benefícios previdenciários se vê limitada diante do envelhecimento populacional e em que a previdência privada busca por formas de compensar a queda de rentabilidade dos ativos financeiros.

\section{Referências Bibliográficas}

Bateman, H. \& Mitchell, O. (2004), 'New evidence on pension plan design and administrative expenses: the Australian experience', Journal of Pension Economics and Finance 3, 63-76.

Bikker, J. \& Dreu, J. (2009), 'Operating costs of pension funds', Journal of Pension Economics and Finance 8, 63-89.

Bikker, J., Steenbeek, O. \& Torracchi, F. (2012), 'The impact of scale, complexity, and service quality on the administrative costs of pension funds: A cross-country comparison', Journal of Risk and Insurance 79, 477-514.

Björkmo, M. \& Lundbergh, S. (2010), 'Restructuring Sweden's ap funds for scale and global impact', Rotman International Journal of Pension Management 3, 30-36.

Brasil (1977), 'Lei 6.435, de 15 de julho de 1977', Congresso Nacional.

Brasil (1978), 'Decreto 81.240, de 20 de janeiro de 1978', Congresso Nacional.

Brasil (1997), 'Lei 9.532, de 10 de dezembro de 1997', Congresso Nacional.

Brasil (2001a), 'Lei complementar 108, de 29 de maio de 2001', Congresso Nacional.

Brasil (2001b), 'Lei complementar 109, de 29 de maio de 2001', Congresso Nacional.

Brasil (2004), 'Lei 11.053, de 29 de dezembro de 2004', Congresso Nacional.

Brasil (2009a), 'Resolução conselho de gestão da previdência complementar 29, de 31 de agosto de 2009', Congresso Nacional.

Brasil (2009b), 'Resolução conselho monetário nacional 3.792, de 28 de setembro de 2009', Congresso Nacional.

Brasil (2012), 'Lei 12.613, de 30 de abril de 2012', Congresso Nacional.

Caswell, J. (1976), 'Economic efficiency in the pension plan administration: a study of the construction industry', Journal of Risk and Insurance 43, 257273.

Coelli, T., Rao, D., O’Donnell, C. \& Battese, G. (2005), An Introduction to Efficiency and Productivity Analysis, 2 edn, Springer.

da Previdência Social, M. (2008), 'Previdência complementar: cartilha do participante'.

URL: http://www.previdencia.gov.br/arquivos/office/3_090119-102133-452.pdf 
da Previdência Social, M. (2011), 'Previdência complementar: o futuro começa agora'.

URL: $h t t p: / / w w w . p r e v i d e n c i a . g o v . b r / a r q u i v o s / o f f i c e / 3 \_110824-163612-814 . p d f$

da Previdência Social, M. (2012), 'Boletim estatístico de previdência social', Congresso Nacional. v. 16 n. 12.

Greene, W. (2012), Econometric Analysis, 7 edn, Pearson Education Limited.

Hsin, P. \& Mitchell, O. (1997), Public pension plan efficiency, in M. Gordon, O. Mitchell \& M. Twinney, eds, 'Positioning Pensions for the 21st Century', University of Pennsylvania Press.

Koh, B., Mitchell, O. \& Fong, J. (2008), 'Cost structures in defined contribution systems: the case of Singapore's central provident fund', Pensions 13, 714 .

Mitchell, O. \& Andrews, E. (1981), 'Scale economies in private multiemployer pension systems', Industrial and Labor Relations Review 34, 522530 .

Scholz, J., Seshari, A. \& Khitatrakun, S. (2006), 'Are americans saving "optimally" for retirement?', Journal of Political Economy 114, 607-643. 
Apêndice A Sumário das Estatísticas Descritivas 


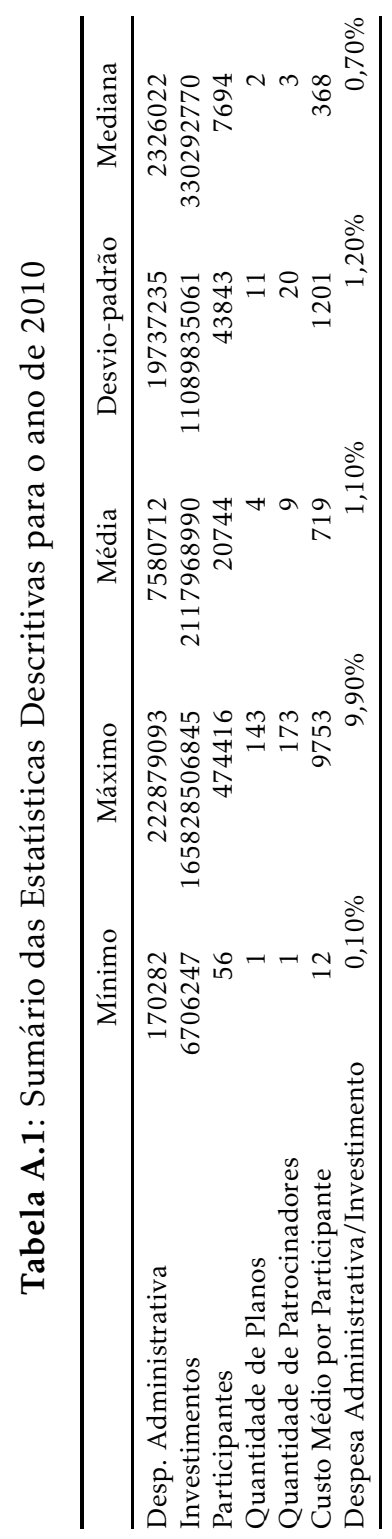




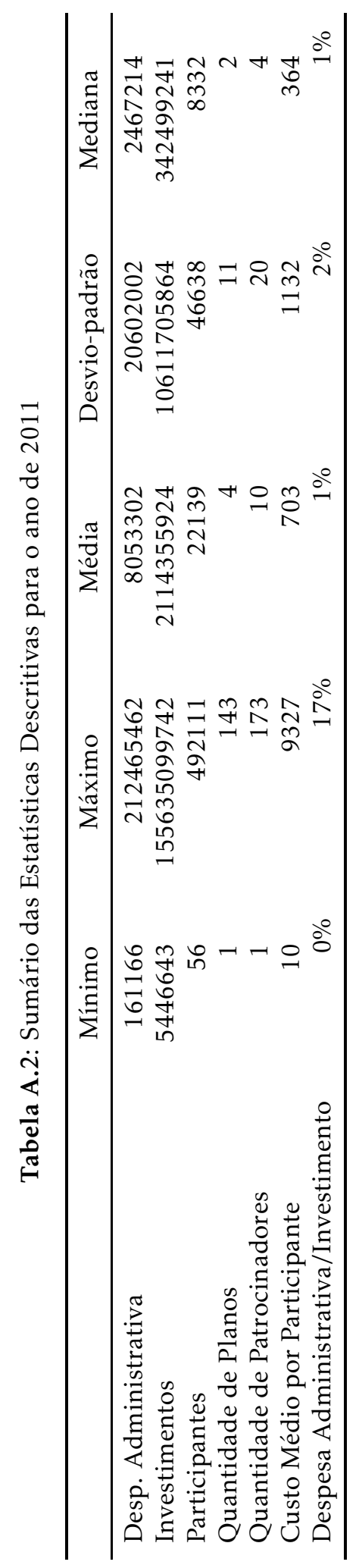


Apêndice B Estimativas de FE para a despesa administrativa em relação às características das EFPC para função do tipo TRANSLOG

Tabela B.1: Estimativas de FE para a despesa administrativa em relação às características das EFPC para função do tipo TRANSLOG

\begin{tabular}{lcl}
\hline & Estimativa & Erro Padrăo \\
\hline (Intercepto) & 26,4426046 & 6,788796 \\
lninv & $-3,047117$ & 0,973581 \\
lnpart & 2,9920075 & 0,877741 \\
dummyprivado & $-1,4406567$ & 1,979456 \\
dummyinstituidor & 4,474023 & 5,161339 \\
lnrelaoapopensat & 0,9528649 & 0,439562 \\
lnQuanPlan & 1,0787677 & 0,999906 \\
lnQuanPatroc & $-0,7938553$ & 0,651307 \\
InvPart & $-0,2452894$ & 0,067126 \\
InvDumPriv & 0,1254911 & 0,135616 \\
InvDumInst & $-0,5868683$ & 0,406424 \\
InvRel & $-0,0955457$ & 0,035308 \\
InvPlan & $-0,0839271$ & 0,069622 \\
InvPatroc & 0,0917046 & 0,046103 \\
InvInv & 0,1381674 & 0,036612 \\
PartPart & 0,1368765 & 0,036232 \\
PartRel & 0,1542391 & 0,035418 \\
PartPriv & $-0,2139878$ & 0,123234 \\
PartInst & 0,7455694 & 0,36713 \\
PartPlan & 0,0488515 & 0,0681 \\
PartPatroc & $-0,0967652$ & 0,046965 \\
RelRel & 0,0545942 & 0,009798 \\
RelPriv & $-0,1495732$ & 0,05862 \\
RelInst & 0,2320296 & 0,190224 \\
RelPlan & 0,0025719 & 0,045237 \\
RelPatroc & $-0,0512691$ & 0,028886 \\
PrivPlan & $-0,0455904$ & 0,119242 \\
PrivPatroc & $-0,0208593$ & 0,125387 \\
InstPlan & 0,1904469 & 0,39281 \\
InstPatroc & 0,3630128 & 0,27549 \\
PlanPlan & 0,2278721 & 0,051972 \\
PlanPatroc & $-0,0707462$ & 0,062269 \\
PatrocPatroc & $-0,0814066$ & 0,037114 \\
sigmaSq & 1,1788662 & 0,138703 \\
gamma & 0,9751466 & 0,004674 \\
time & $-0,0033171$ & 0,014497 \\
\hline & & \\
\hline
\end{tabular}

